\title{
Analisa Penggunaan Sumber Daya Manusia Dengan Metode Resource Leveling Pada Pelaksanaan Proyek Konstruksi (Studi Kasus : Proyek Pembangunan Ruang Kelas Baru Ponpes Daarun Nahdah Thawalib Bangkinang)
}

\author{
Deddy Purnomo Retno ${ }^{1}$, Astuti $^{2}$, Zulfadli Tamimi ${ }^{3}$ \\ ${ }^{1,2}$ Dosen Program Studi Teknik Sipil, Universitas Islam Riau \\ ${ }^{3}$ Mahasiswa Program Studi Teknik Sipil, Universitas Islam Riau
}

\begin{abstract}
Abstrak
Tenaga kerja merupakan salah satu sumber daya manusia yang penting, karena seringkali penyediaannya terbatas, baik karena faktor kualitas maupun hal-hal lain. Kemudian kelebihan tenaga keja akan mengakibatkan pemborosan biaya serta kekurangan tenaga kerja akan mengakibatkan keterlambatan pelaksanaan proyek yang telah dijadwalkan. Tujuan tugas akhir ini adalah untuk menentukan sumber daya manusia yang efektif dalam pelaksanaan proyek Pembangunan Ruang Kelas Baru Ponpes Daarun Nahdah Thawalib Bangkinang, dan untuk mengetahui berapa banyak biaya yang diperlukan untuk kebutuhan penggunaan sumber daya manusia.

Metode Perataan Sumber Daya (Resource Leveling) dapat digunakan untuk mendapatkan histogram penggunaan tenaga kerja yang efektif dalam pelaksanaan proyek konstruksi sehingga tidak terjadi penurunan dan peningkatan penggunaan tenaga kerja diawal, ditengah dan diakhir jadwal pelaksanaan pekerjaan. Proses Resource Leveling dilakukan menggunakan bantuan aplikasi Microsoft Project 2013.

Dari hasil penelitian diperoleh penggunaan tenaga kerja rencana dan tenaga keja setelah perataan (leveling) yaitu sebanyak 790 orang dengan biaya sebesar Rp. 375.270.000,00 yang terdiri dari 470 orang pekerja dengan biaya sebesar Rp. 207.270.000,00 dan 320 orang tukang dengan biaya sebesar Rp. 168.000.000,00. Sedangkan tenaga kerja realisasi atau lapangan sebanyak 831 orang dengan biaya sebesar Rp. 382.011.000,00 yang terdiri dari 646 orang pekerja dengan biaya sebesar Rp. $284.886 .000,00$ dan 185 orang tukang dengan biaya sebesar Rp. 97.125.000,00. Dengan demikian tenaga kerja rencana dan setelah perataan lebih hemat biaya sebesar Rp. 6.741.000,00 dibandingkan tenaga kerja realisasi.
\end{abstract}

Kata kunci : pekerja, resource leveling, sumber daya, tenaga kerja, tukang.

\begin{abstract}
Labor is one of the most important human resources, because it is often limited in provision, both because of the quality factor and other things. Then the excess work force will lead to waste of costs and labor shortages will result in delays in the implementation of projects that have been scheduled. The purpose of this thesis is to determine the effective human resources in the implementation of the New Classroom Building Project Ponpes Daarun Nahdah Thawalib Bangkinang, and to find out how much cost is needed for the needs of human resource use.

Resource Leveling Methods can be used to obtain an effective employment histogram in the implementation of a construction project so that there is no decrease and increased use of labor at the beginning, middle and end of the job execution schedule. The Resource Leveling process is done using Microsoft Project 2013 help.

From the result of the research, it is found that the use of workforce of plan and work force after leveling is 790 people with the cost of Rp. 375,270,000.00, consisting of 470 workers at a cost of Rp. 207.270.000,00 and 320 craftsmen at a cost of Rp. 168,000,000.00. While the labor realization or field as many as 831 people with a fee of Rp. 382.011.000,00 consisting of 646 workers with a fee of Rp. 284,886,000,00 and 185 carpenters at a cost of Rp. 97.125.000,00. Thus the workforce of the plan and after smoothing is more cost effective at Rp. $6,741,000.00$ compared to realization workforce.
\end{abstract}

Keywords: worker, resource leveling, resources, manpower, builders. 


\section{PENDAHULUAN}

\section{Latar Belakang Masalah}

Proyek konstruksi merupakan suatu rangkaian kegiatan yang saling berkaitan untuk mencapai tujuan tertentu yaitu bangunan atau konstruksi dalam batasan waktu, biaya dan mutu tertentu. Proyek konstruksi selalu memerlukan sumber daya yaitu manusia, material atau bahan bangunan, peralatan, metode pelaksanaan, biaya atau uang, informasi, dan waktu (Kerzner, 2006).

Seiring pesatnya perkembangan proyek konstruksi di Indonesia serta laju pertumbuhan penduduk yang semakin tinggi, hal ini membuat semakin banyaknya kebutuhan akan fasilitas yang harus dikembangkan terutama dibidang pembangunan. Untuk mencermati perkembangan tersebut, Provinsi Riau juga akan meningkatkan pembangunan disegala bidang terutama dibidang pendidikan, seperti pembangunan ruang kelas baru Ponpes Daarun Nahdah Thawalib. Pembangunan ini berlokasi di jalan Raya Bangkinang-Petapahan Kabupaten Kampar Provinsi Riau.

Dalam pelaksanaan suatu proyek konstruksi adakalanya terjadi kendalakendala yang dihadapi di lapangan, seperti terjadi keterlambatan pelaksanaan pekerjaan akibat faktor cuaca yang tidak bisa diprediksi, material yang jauh dari lokasi pekerjaan, pelaksanaan yang tidak sesuai dengan penjadwalan yang telah ditentukan, serta penggunaan sumber daya manusia yang tidak efisien. Pada penelitian ini yang akan dibahas tentang penggunaan sumber daya manusia yang tidak efisien.

Tenaga kerja merupakan salah satu sumber daya manusia yang penting, seringkali penyediaannya terbatas, baik karena faktor kualitas ataupun hal-hal lain. Merekrut, menyeleksi, dan melatih tenaga kerja memerlukan biaya mahal dan membutuhkan waktu lama sebelum mereka siap pakai. Setelah mereka bergabung dengan proyek, tidak mudah untuk melepas dan memanggil kembali untuk bekerja sesuai dengan fluktuasi pekerjaan yang tersedia. Sedangkan menahan mereka untuk stand-by akan menelan biaya yang dipandang tidak efisien atau efektif (Soeharto, 1999).

Untuk mengetahui sumber daya manusia yang efisien atau efektif dalam pelaksanaan proyek konstruksi digunakanlah metode perataan sumber daya (Resource Leveling). Perataan sumber daya adalah meratakan frekuensi alokasi sumber daya dengan tujuan memastikan jumlah atau jenis sumber daya dapat diketahui dari awal dan tersedia bila dibutuhkan. Tujuan dari perataan sumber daya adalah untuk menyesuaikan ketersedian sumber daya dengan jadwal kegiatan dengan pola penyebaran yang logis sehingga durasi proyek tidak melampaui batas berlebihan. Variasi penyebaran sumber daya dari suatu periode ke periode lainnya diusahakan dapat tetap pada suatu batas minimum kebutuhannya, sehingga hasil yang dicapai dapat memenuhi sesuai dengan kemampuan dan ketersedian sumber daya yang ada (Husein, 2008).

Bertolak dari gambaran permasalahan tersebut penelitian ini melakukan analisa terhadap penggunaan sumber daya manusia pada pelaksanaan Proyek Pembangunan Ruang Kelas Baru Ponpes Daarun Nahdah Thawalib Bangkinang dengan cara meratakan sumber daya manusia menggunakan metode Perataan Sumber Daya (Resource Leveling).

\section{Rumusan Masalah}

Berdasarkan latar belakang masalah yang telah dipaparkan di atas, maka dapat dirumuskan permasalahan sebagai berikut :

1. Bagaimana penggunaan sumber daya manusia yang efektif dalam pelaksanaan proyek Pembangunan Ruang Kelas Baru Ponpes Daarun Nahdah Thawalib Bangkinang?

2. Berapa banyak biaya yang diperlukan untuk kebutuhan penggunaan sumber daya manusia? 


\section{Tujuan Penelitian}

Dari rumusan masalah yang telah dijelaskan di atas, maka di dapat tujuan penelitian sebagai berikut:

1. Menentukan sumber daya manusia yang efektif dalam pelaksanaan proyek Pembangunan Ruang Kelas Baru Ponpes Daarun Nahdah Thawalib Bangkinang.

2. Menghitung berapa banyak biaya yang diperlukan untuk kebutuhan penggunaan sumber daya manusia.

\section{METODOLOGI PENELITIAN Lokasi Penelitian}

Proyek Pembangunan Ruang Kelas Baru Ponpes Daarun Nahdah Thawalib Bangkinang 6 Lokal Konstruksi Bertingkat 3 Lantai ini dilakukan di Bangkinang Kabupaten Kampar Provinsi Riau tepatnya di jalan Raya Bangkinang-Petapahan. Untuk lebih jelasnya bisa dilihat gambar denah lokasi penelitian sebagai berikut:

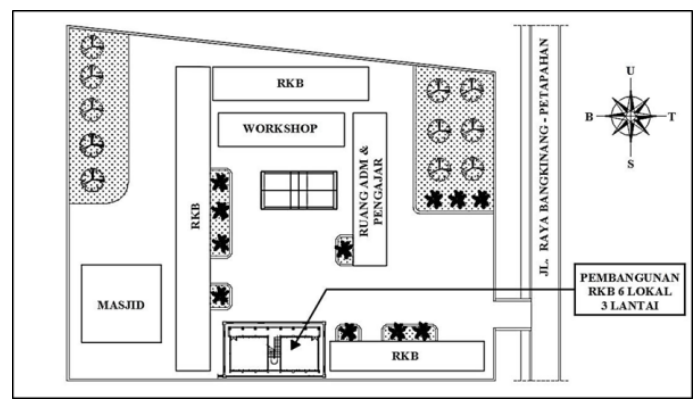

Gambar 1. Denah Lokasi Penelitian

\section{Gambaran Umum Proyek}

Gambaran umum proyek merupakan informasi tentang bangunan yang akan dijadikan sebagai objek dalam penyusunan tugas akhir. Pada tugas akhir ini yang akan dijadikan objek penelitian adalah pembangunan ruang kelas baru Ponpes Daarun Bangkinang. Untuk lebih jelasnya dapat dilihat data-data proyek yang akan dibangun sebagai berikut:

1. Kegiatan : Pembanguan dan Pengadaan Sarana dan Prasarana Pendidikan dan Kebudayaan (Bantuan Keuangan Provinsi).

2. Pekerjaan : Pembangunan Ruang Kelas Baru Ponpes Daarun
3. Nahdah Thawalib Bangkinang 6 Lokal Kontruksi

4. Bertingkat 3 Lantai Kec. Bangkinang

5. Lokasi : Kabupaten Kampar

6. Waktu Pelaksanaan : 112 hari (16 minggu)

7. Mulai elaksanaa :06 September 2016

8. Selesai Pelaksanaan : 26 Desember 2016

9. Kontraktor Pelaksana : CV. Juli Sejahtera

10. Konsultan Pengawas: PT. Calvindam Jaya

\section{Teknik Pengumpulan Data}

Teknik pengumpulan data merupakan cara-cara yang digunakan untuk mendapatkan data yang berkaitan dengan judul penelitian. Jenis data yang digunakan dalam penelitian ini adalah data sekunder. Data Sekunder merupakan data yang dikumpulkan peneliti dari sumber yang sudah ada dalam artian peneliti sebagai tangan kedua. Data sekunder dalam penelitian ini diperoleh dari kontraktor pelaksana proyek berupa dokumendokumen proyek yang dijadikan sebagai sumber data penelitian. Data sekunder tersebut adalah sebagai berikut:

1. Rencana Anggaran Biaya (RAB).

2. Analisa Harga Satua Pekerjaan (AHSP).

3. Data Tenaga Kerja Proyek.

4. Daftar Harga Upah dan Bahan

5. Time Schedule

6. Gambar Rencana Proyek.

\section{Analisa Data}

Tahapan dalam analisa data merupakan urutan langkah yang dilaksanakan secara sistematis dan logis sesuai dasar teori permasalahan sehingga didapat analisa yang akurat untuk mencapai tujuan penulisan. Tahapan Penelitian

Tahapan penelitian adalah tahap-tahap yang dilakukan peneliti secara berurutan selama berlangsungnya penelitian. Tahapan penelitian ini memeberikan gambaran secara garis besar langkah-langkah pelaksanaan penelitian yang akan menuntun 
peneliti agar lebih terarah selama berjalannya penelitian. Adapun tahapan pelaksanaan penelitian dalam penyusunan tugas akhir ini adalah sebagai berikut:

1. Mulai

Mulai adalah langkah awal sebelum melakukan persiapan dalam penelitian.

2. Tahapan Persiapan

Tahapan persiapan merupakan langkah utama yang dilakukan yaitu, mempersiapkan gambaran tentang skripsi yang akan dilakukan serta memilih masalah yang pantas untuk diteliti. Kemudian mencari tempat atau lokasi penelitian yang akan dilakukan.

3. Pengumpulan Data

Dalam penelitian ini penulis memerlukan beberapa data dan literatur untuk pembahasan dalam menyelesaikan penelitian ini. Data-data tersebut didapat dari Kontraktor Pelaksana.

4. Analisa Data

Setelah pengumpulan data dilanjutkan dengan analisa data, yaitu menghitung durasi pekerjaan dan menghitung kebutuhan tenaga kerja. Selanjutnya pengolahan data menggunakan Microsoft Project 2013 untuk mendapatkan histogram tenaga kerja kemudian dilakukan proses perataan (Levelling) untuk mendapatkan histogram kebutuhan sumber daya manusia yang ideal.

5. Hasil dan pembahasan

Hasil dan pembahasan yaitu membahas hasil-hasil yang disederhanakan dalam bentuk tabel, grafik atau lainnya, agar mempermudah pemahaman hasil analisa bagi pembaca.

6. Kesimpulan dan saran

Kesimpulan dan saran yaitu membuat kesimpulan yang diambil dari hasil penelitian dan memberikan saran kepada pembaca tentang analisa penggunaan tenaga kerja pada pelaksanaan proyek konstruksi.

7. Selesai
Langkah-langkah penelitian dalam penyusunan tugas akhir ini dapat dilihat pada bagan alir (Flow Chart) penelitian berikut:

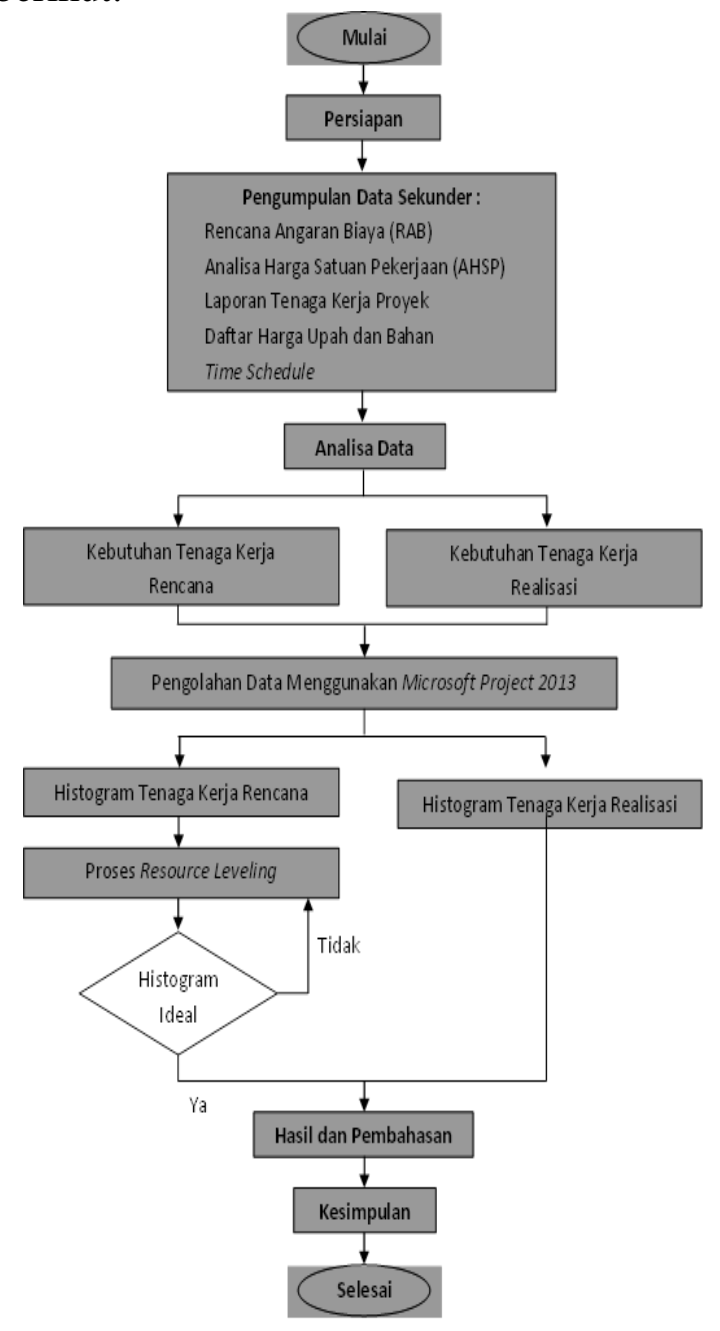

Gambar 2. Bagan Alir Penelitian

\section{HASIL DAN PEMBAHASAN \\ Histogram Sumber Daya Manusia}

Sumber daya manusia dalam dalam Tugas Akhir ini adalah tenaga kerja yang berupa pekerja dan tukang. Tukang yang dimaksud adalah tenaga kerja yang ahli dalam bidangnya masing-masing berdasarkan pengalaman dan cara kerja yang sederhana, sedangkan pekerja adalah tenaga kerja yang bertugas membantu apa saja yang dibutuhkan oleh tukang.

Histogram sumber daya manusia dalam penelitian ini menggambarkan penggunaan tenaga kerja dari mulai proyek pada minggu ke-1 dan selesai pada minggu ke-16. 


\section{Histogram Tenaga Kerja Rencana}

Histogram tenaga kerja rencana diperoleh dari hasil perhitungan jumlah tenaga kerja rencana yang kemudian dimasukkan kedalam aplikasi Microsoft Project 2013 (Lampiran A). Histogram tenaga kerja rencana tersebut bisa dilihat pada gambar berikut:

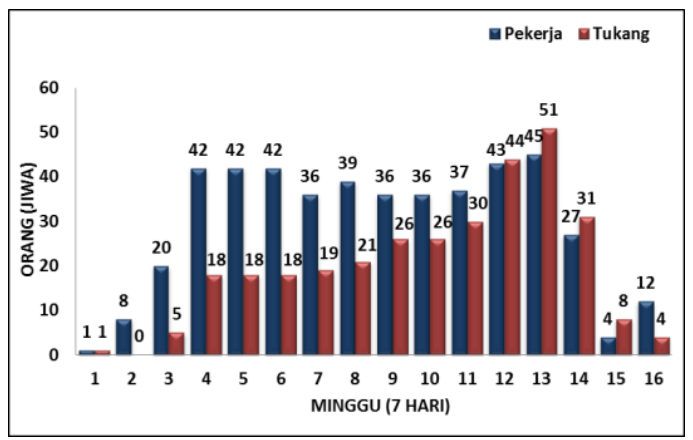

Gambar 3. Histogram Tenaga Kerja Rencana

Histogram tenaga kerja rencana menggambarkan kebutuhan tenaga kerja setiap minggu berdasarkan kebutuhan tenaga kerja yang dihitung menggunakan koefisien SNI 2013. Sehingga dari Gambar 5.1 dapat dirincikan sebagai berikut:

1. Kebutuhan pekerja terendah yaitu sebanyak 1 orang pada minggu ke- 1 .

2. Kebutuhan pekerja tertinggi yaitu sebanyak 51 orang pada minggu ke-13.

3. Kebutuhan tukang terendah yaitu sebanyak 0 orang pada minggu ke- 2 .

4. Kebutuhan tukang tertinggi yaitu sebanyak 31 orang pada minggu ke-14.

\section{Histogram Tenaga Kerja Realisasi}

Histogram tenaga kerja realisasi diperoleh dari hasil perhitungan jumlah tenaga kerja realisasi yang kemudian dimasukkan kedalam aplikasi Microsoft Project 2013 untuk mendapatkan histogram sumber daya manusia (Lampiran A). Histogram tenaga kerja realisasi tersebut bisa dilihat pada gambar berikut:

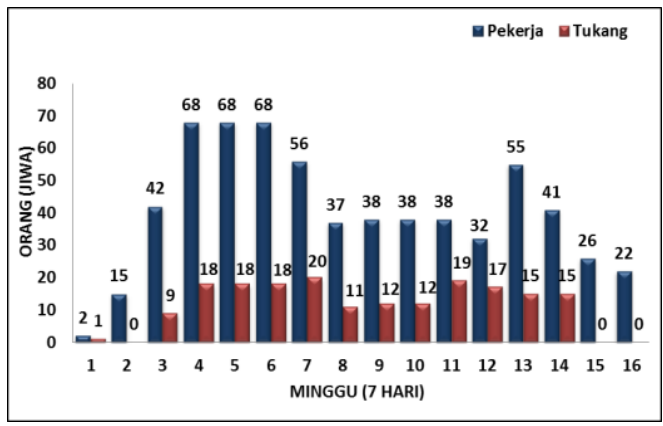

Gambar 4. Histogram Tenaga Kerja Realisasi

Histogram tenaga kerja realisasi menggambarkan kebutuhan tenaga kerja setiap minggu berdasarkan kebutuhan tenaga kerja dilapangan. Sehingga dari Gambar 5.2 dapat dirincikan sebagai berikut:

1. Kebutuhan pekerja terendah yaitu sebanyak 2 orang pada minggu ke- 1 .

2. Kebutuhan pekerja tertinggi yaitu sebanyak 68 orang pada minggu ke-4, ke-5, dan ke-6.

3. Kebutuhan tukang terendah yaitu sebanyak 0 orang pada minggu ke-2, ke-15, dan ke-16.

4. Kebutuhan tukang tertinggi yaitu sebanyak 18 orang pada minggu ke-4, ke-5, dan ke-6.

\section{Histogram Tenaga Kerja Hasil Resource Leveling}

Histogram tenaga kerja hasil perataan sumber daya (resource leveling) diperoleh dari perataan tenaga kerja rencana menggunakan aplikasi Microsoft Project 2013 (Lampiran A). Histogram tenaga kerja hasil resource leveling tersebut bisa dilihat pada gambar berikut: 


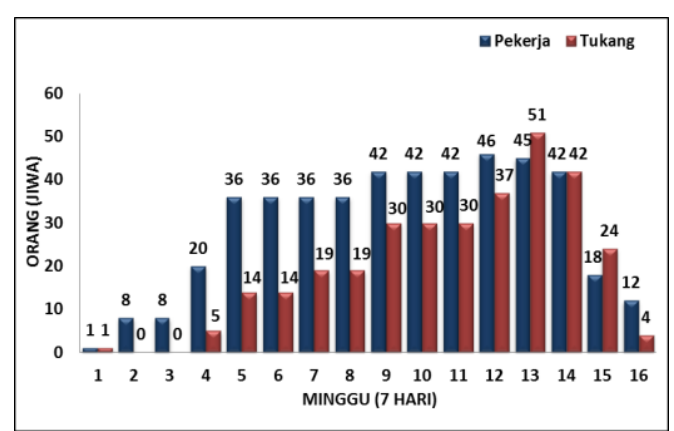

Gambar 5. Histogram Tenaga Kerja Hasil Resource Leveling

Histogram tenaga kerja hasil resource leveling menggambarkan kebutuhan tenaga kerja setiap minggu berdasarkan kebutuhan tenaga kerja rencana yang diratakan. Sehingga dari Gambar 5.3 dapat dirincikan sebagai berikut:

1. Kebutuhan pekerja terendah yaitu sebanyak 1 orang pada minggu ke-1.

2. Kebutuhan pekerja tertinggi yaitu sebanyak 46 orang pada minggu ke-12.

3. Kebutuhan tukang terendah yaitu sebanyak 0 orang pada minggu ke-2 dan ke-3.

4. Kebutuhan tukang tertinggi yaitu sebanyak 51 orang pada minggu ke-13.

Dari histogram tenaga kerja rencana, realisasi, dan hasil resource leveling, maka tenaga kerja hasil resource leveling lebih efektif karena:

1. Penggambaran histogram tenaga kerja realisasi terlalu banyak penurunan dan peningkatan penggunaan tenaga kerja (pekerja dan tukang) baik diawal, ditengah dan diakhir jadwal pelaksanaan pekerjaan.

2. Penggambaran histogram pekerja tenaga kerja rencana terlalu banyak penurunan dan peningkatan penggunaan pekerja diawal, ditengah dan diakhir jadwal pelaksanaan pekerjaan.

3. Penggambaran histogram tenaga kerja hasil resource leveling lebih efektif karena peningkatan dan penurunan kebutuhan tenaga kerja secara bertahap sehingga tidak terjadi fluktuasi penggunaan tenaga kerja yang tajam.
Setelah proses Resource Leveling terjadi perubahan jadwal pekerjaan dan lintasan kritis karena penggeseran beberapa pekerjaan pada proses perataan (Lampiran A). Perubahan jadwal tersebut bisa dilihat pada tabel berikut :

Tabel 1. Perubahan Jadwal Pekerjaan

\begin{tabular}{llllll}
\hline No & $\begin{array}{l}\text { Pekerja } \\
\text { an }\end{array}$ & \multicolumn{2}{c}{ Jadwal Awal } & \multicolumn{2}{c}{$\begin{array}{c}\text { Perubahan } \\
\text { Jadwal }\end{array}$} \\
& Mulai & $\begin{array}{c}\text { Selesa } \\
\text { i }\end{array}$ & Mulai & $\begin{array}{c}\text { Selesa } \\
\text { i }\end{array}$ \\
\hline 1. & $\begin{array}{l}\text { Pekerjaan } \\
\text { Pondasi } \\
\text { Pekerjaan }\end{array}$ & $20 / 09 / 16$ & $24 / 10 / 16$ & $27 / 09 / 16$ & $31 / 10 / 16$ \\
2. & $\begin{array}{l}\text { Struktur } \\
\text { Beton }\end{array}$ & $27 / 09 / 16$ & $21 / 11 / 16$ & $04 / 10 / 16$ & $28 / 11 / 16$ \\
3. $\begin{array}{l}\text { Pekerjaan } \\
\text { Dinding \& } \\
\text { Plester }\end{array}$ & $25 / 10 / 16$ & $05 / 12 / 16$ & $01 / 11 / 16$ & $12 / 12 / 16$ \\
4. & $\begin{array}{l}\text { Pekerjaan } \\
\text { Alat }\end{array}$ & $15 / 11 / 16$ & $05 / 12 / 16$ & $22 / 11 / 16$ & $12 / 12 / 16$ \\
$\begin{array}{l}\text { Pengantung } \\
\text { Pekerjaan } \\
\text { Langit- }\end{array}$ & $22 / 11 / 16$ & $12 / 12 / 16$ & $29 / 11 / 16$ & $19 / 12 / 16$ \\
5. & $\begin{array}{l}\text { Langit / } \\
\text { Plafond } \\
\text { Pekerjaan } \\
\text { Atap } \\
\text { Pekerjaan } \\
\text { Elektrikal }\end{array}$ & $06 / 12 / 16$ & $12 / 12 / 16$ & $13 / 12 / 16$ & $19 / 12 / 16$ \\
\hline & & & & \\
\hline
\end{tabular}

Dari Tabel 5.1 dapat dirincikan sebagai berikut:

1. Pekerjaan pondasi 1 minggu lebih lambat dari jadwal rencana yaitu dari tanggal 20 September 2016 sampai dengan tanggal 27 September 2016 berubah menjadi tanggal 27 September 2016 sampai tanggal 31 Oktober 2016.

2. Pekerjaan struktur beton 1 minggu lebih lambat dari jadwal rencana yaitu dari tanggal 27 September 2016 sampai dengan tanggal 21 November 2016 berubah menjadi tanggal 4 Oktober 2016 sampai tanggal 28 November 2016.

3. Pekerjaan dinding dan plester 1 minggu lebih lambat dari jadwal rencana yaitu dari tanggal 25 Oktober 2016 sampai dengan tanggal 5 Desember 2016 berubah menjadi tanggal 1 November 2016 sampai tanggal 12 Desember 2016. 
4. Pekerjaan alat penggantung 1 minggu lebih lambat dari jadwal rencana yaitu dari tanggal 15 November 2016 sampai dengan tanggal 5 Desember 2016 berubah menjadi tanggal 22 November 2016 sampai tanggal 12 Desember 2016.

5. Pekerjaan langit-langit/plafond 1 minggu lebih lambat dari jadwal rencana yaitu dari tanggal 22 November 2016 sampai dengan tanggal 12 Desember 2016 berubah menjadi tanggal 29 November 2016 sampai tanggal 19 Desember 2016.

6. Pekerjaan atap 1 minggu lebih lambat dari jadwal rencana yaitu dari tanggal 22 November 2016 sampai dengan tanggal 12 Desember 2016 berubah menjadi tanggal 29 November 2016 sampai tanggal 19 Desember 2016.

7. Pekerjaan elektrikal 1 minggu lebih lambat dari jadwal rencana yaitu dari tanggal 6 Desember 2016 sampai dengan tanggal 12 Desember 2016 berubah menjadi tanggal 13 Desember 2016 sampai tanggal 19 Desember 2016.

Perubahan lintasan kritis yang terjadi karena proses perataan sumber daya adalah sebagai berikut:

1. Lintasan kritis awal

: Pekerjaan

$\mathrm{A}-\mathrm{B}-\mathrm{E}-\mathrm{M}-\mathrm{N}$

: Pekerjaan

2. Lintasan kritis baru $\mathrm{A}-\mathrm{C}-\mathrm{F}-\mathrm{K}-\mathrm{N}$

3. Lintasan kritis baru

: Pekerjaan

$\mathrm{A}-\mathrm{D}-\mathrm{I}-\mathrm{N}$

Kemudian dari histogram tenaga kerja rencana, tenaga kerja realisasi, dan tenaga kerja hasil resource leveling diperoleh penggunaan tenaga kerja setiap minggu (Lampiran A). Dari penggunaan tenaga kerja tersebut maka perbandingan jumlah dan total tenaga kerja adalah sebagai berikut:

Tabel 2. Perbandingan Jumlah dan Total Tenaga Kerja

\begin{tabular}{ccc}
$\begin{array}{c}\text { Minggu } \\
(\text { Weeks }\end{array}$ & \multicolumn{3}{c}{ Tenaga Kerja (Orang dalam minggu atau } \\
) & Rencana & OM) \\
& Realisasi & Setelah
\end{tabular}

\begin{tabular}{ccccccc} 
& & & & \multicolumn{3}{c}{ Peratan } \\
& $\begin{array}{c}\text { Pek } \\
\text { erja }\end{array}$ & $\begin{array}{c}\text { Tuka } \\
\text { ng }\end{array}$ & $\begin{array}{c}\text { Peke } \\
\text { rja }\end{array}$ & $\begin{array}{c}\text { Tuka } \\
\text { ng }\end{array}$ & $\begin{array}{c}\text { Peke } \\
\text { rja }\end{array}$ & $\begin{array}{c}\text { Tuka } \\
\text { ng }\end{array}$ \\
\hline 1 & 1 & 1 & 2 & 1 & 1 & 1 \\
2 & 8 & - & 15 & - & 8 & - \\
3 & 20 & 5 & 42 & 9 & 8 & - \\
4 & 42 & 18 & 68 & 18 & 20 & 5 \\
5 & 42 & 18 & 68 & 18 & 36 & 14 \\
6 & 42 & 18 & 68 & 18 & 36 & 14 \\
7 & 36 & 19 & 56 & 20 & 36 & 19 \\
8 & 39 & 21 & 37 & 11 & 36 & 19 \\
9 & 36 & 26 & 38 & 12 & 42 & 30 \\
10 & 36 & 26 & 38 & 12 & 42 & 30 \\
11 & 37 & 30 & 38 & 19 & 42 & 30 \\
12 & 43 & 44 & 32 & 17 & 46 & 37 \\
13 & 45 & 51 & 55 & 15 & 45 & 51 \\
14 & 27 & 31 & 41 & 15 & 42 & 42 \\
15 & 4 & 8 & 26 & - & 18 & 24 \\
16 & 12 & 4 & 22 & - & 12 & 4 \\
Jumlah & 470 & 320 & 646 & 185 & 470 & 320 \\
(OM) & & & & & & \\
\hline Total & & & & & & \\
(OM) & & & & & & \\
\hline
\end{tabular}

Dari Tabel 5.2 dapat dirincikan sebagai berikut:

1. Jumlah tenaga kerja rencana sama dengan tenaga kerja setelah perataan, yaitu sebanyak 470 orang pekerja dan 320 orang tukang.

2. Penggunaan tenaga kerja rencana berbeda dengan tenaga kerja setelah perataan, yaitu pada minggu ke $3,4,5$, $6,8,9,10,11,12,14$, dan 15 .

3. Jumlah pekerja tenaga kerja realisasi lebih banyak menggunakan pekerja dibandingkan tenaga kerja rencana dan tenaga kerja setelah perataan.

4. Jumlah tukang tenaga kerja realisasi lebih sedikit menggunakan tukang dibandingkan tenaga kerja rencana dan tenaga kerja setelah perataan.

5. Total tenaga kerja realisasi lebih banyak menggunakan dibandingkan tenaga kerja rencana dan tenaga kerja setelah perataan.

\section{Perbandingan Biaya Tenaga Kerja}

Biaya tenaga kerja dihitung berdasarkan histogram tenaga kerja rencana, tenaga kerja realisasi, dan tenaga kerja hasil resource leveling yang bisa 
dilihat pada Lampiran A. Untuk lebih jelasnya bisa dilihat pada tabel berikut:

Tabel 3. Perbandingan Biaya Tenaga Kerja

\begin{tabular}{|c|c|c|c|}
\hline \multirow{2}{*}{$\begin{array}{c}\text { Ming } \\
\text { gu } \\
(\text { Week } \\
s)\end{array}$} & \multicolumn{3}{|c|}{ Biaya Tenaga Kerja } \\
\hline & Rencana & Realisasi & $\begin{array}{c}\text { Setelah } \\
\text { Perataan }\end{array}$ \\
\hline 1 & Rp.966.000,- & $\begin{array}{l}\text { Rp.1.407.000, } \\
\text { - }\end{array}$ & Rp.966.000,- \\
\hline 2 & $\begin{array}{l}\text { Rp.3.528.00 } \\
0,-\end{array}$ & Rp.6.615.000, & $\begin{array}{l}\text { Rp.3.528.000, } \\
-\end{array}$ \\
\hline 3 & $\begin{array}{l}\text { Rp.11.445.0 } \\
00,-\end{array}$ & $\begin{array}{l}\text { Rp.23.247.00 } \\
0,-\end{array}$ & $\begin{array}{l}\text { Rp.3.528.000, } \\
-\end{array}$ \\
\hline 4 & $\begin{array}{l}\text { Rp.27.972.0 } \\
00,-\end{array}$ & $\begin{array}{l}\text { Rp.39.438.00 } \\
0,-\end{array}$ & $\begin{array}{l}\text { Rp.11.445.00 } \\
0,-\end{array}$ \\
\hline 5 & $\begin{array}{l}\text { Rp.27.972.0 } \\
00,-\end{array}$ & $\begin{array}{l}\text { Rp.39.438.00 } \\
0,-\end{array}$ & $\begin{array}{l}\text { Rp.23.226.00 } \\
0,-\end{array}$ \\
\hline 6 & $\begin{array}{l}\text { Rp.27.972.0 } \\
00,-\end{array}$ & $\begin{array}{l}\text { Rp.39.438.00 } \\
0,-\end{array}$ & $\begin{array}{l}\text { Rp.23.226.00 } \\
0,-\end{array}$ \\
\hline 7 & $\begin{array}{l}\text { Rp.25.851.0 } \\
00,-\end{array}$ & $\begin{array}{l}\text { Rp.35.196.00 } \\
0,-\end{array}$ & $\begin{array}{l}\text { Rp.25.851.00 } \\
0,-\end{array}$ \\
\hline 8. & $\begin{array}{l}\text { Rp.28.224.0 } \\
00,-\end{array}$ & $\begin{array}{l}\text { Rp.22.092.00 } \\
0,-\end{array}$ & $\begin{array}{l}\text { Rp.25.851.00 } \\
0,-\end{array}$ \\
\hline 9 & $\begin{array}{l}\text { Rp.29.526.0 } \\
00,-\end{array}$ & $\begin{array}{l}\text { Rp.23.058.00 } \\
0,-\end{array}$ & $\begin{array}{l}\text { Rp.34.272.00 } \\
0,-\end{array}$ \\
\hline 10 & $\begin{array}{l}\text { Rp.29.526.0 } \\
00,-\end{array}$ & $\begin{array}{l}\text { Rp.23.058.00 } \\
0,-\end{array}$ & $\begin{array}{l}\text { Rp.34.272.00 } \\
0,-\end{array}$ \\
\hline 11 & $\begin{array}{l}\text { Rp.32.067.0 } \\
00,-\end{array}$ & $\begin{array}{l}\text { Rp.26.733.00 } \\
0,-\end{array}$ & $\begin{array}{l}\text { Rp.34.272.00 } \\
0,-\end{array}$ \\
\hline 12 & $\begin{array}{l}\text { Rp.42.063.0 } \\
00,-\end{array}$ & $\begin{array}{l}\text { Rp.23.037.00 } \\
0,-\end{array}$ & $\begin{array}{l}\text { Rp.39.711.00 } \\
0,-\end{array}$ \\
\hline 13 & $\begin{array}{l}\text { Rp.46.620.0 } \\
00,-\end{array}$ & $\begin{array}{l}\text { Rp.32.130.00 } \\
0,-\end{array}$ & $\begin{array}{l}\text { Rp.46.620.00 } \\
0,-\end{array}$ \\
\hline 14 & $\begin{array}{l}\text { Rp.28.182.0 } \\
00,-\end{array}$ & $\begin{array}{l}\text { Rp.25.956.00 } \\
0,-\end{array}$ & $\begin{array}{l}\text { Rp.40.572.00 } \\
0,-\end{array}$ \\
\hline 15 & $\begin{array}{l}\text { Rp.5.964.00 } \\
0,-\end{array}$ & $\begin{array}{l}\text { Rp.11.466.00 } \\
0,-\end{array}$ & $\begin{array}{l}\text { Rp.20.538.00 } \\
0,-\end{array}$ \\
\hline 16 & $\begin{array}{l}\text { Rp.7.392.00 } \\
0,-\end{array}$ & $\begin{array}{l}\text { Rp.9.702.000, } \\
\text { - }\end{array}$ & $\begin{array}{l}\text { Rp.7.392.000, } \\
\text { - }\end{array}$ \\
\hline Total & $\begin{array}{l}\text { Rp.375.270. } \\
\text { 000,- }\end{array}$ & $\begin{array}{l}\text { Rp.382.011.0 } \\
\text { 00,- }\end{array}$ & $\begin{array}{l}\text { Rp.375.270.0 } \\
\text { 00,- }\end{array}$ \\
\hline
\end{tabular}
berikut:

1. Biaya tenaga kerja realisasi sebesar Rp. 382.011.000,00 lebih banyak dibandingkan biaya tenaga kerja rencana dan tenaga kerja setelah perataan yaitu sebesar Rp. 375.270.000,00.

2. Biaya tenaga kerja rencana sama dengan tenaga kerja setelah perataan karena jumlah tenaga kerjanya sama.

3. Tenaga kerja rencana dan tenaga kerja setelah perataan bisa menghemat biaya sebesar Rp. 6.741.000,00.

\section{Hasil Analisis Penelitian Sejenis Sebelumnya}

Sumber daya manusia pada pelaksanaan setiap proyek konstruksi memiliki kebutuhan yang berbeda-beda kerena volume dan durasi pekerjaan pada setiap proyek tidak sama.

Berdasarkan penelitian yang dilakukan oleh Purwanto (2010) pada pembangunan gedung yang ditinjau menggunakan metode Resource Leveling bisa meminimalisir penggunaan tenaga kerja sebanyak 802 orang dan menghemat biaya sebesar Rp. 31.173.000,00. Dari hasil tersebut penulis ingin mengetahui penggunaan tenaga kerja pada pelaksanaan proyek konstruksi yang sedang ditinjau menggunakan metode yang sama yaitu resource leveling. Dari penelitian yang telah dilakukan diperoleh tenaga kerja yang direncanakan lebih efisien dengan selisih jumlah tenaga kerja sebanyak 41 orang dan bisa menghemat biaya sebesar Rp. 6.741.000,00. Jadi dapat disimpulkan bahwa perencanaan tenaga kerja pada pelaksanaan proyek konstruksi menggunakan metode Resource Leveling bisa menghasilkan tenaga kerja yang efisien dan ideal.

\section{KESIMPULAN DAN SARAN}

\section{Kesimpulan}

Berdasarkan hasil penelitian tentang Analisa Penggunaan Sumber Daya Manusia dengan metode Resource Leveling pada Pelaksanaan Proyek Konstruksi, maka diambil kesimpulan antara lain sebagai berikut:

1. Jumlah tenaga kerja rencana yaitu sebanyak 790 orang yang terdiri dari 470 orang pekerja dan 320 orang tukang, jumlah tenaga kerja realisasi atau lapangan sebanyak 831 orang yang terdiri dari 646 orang pekerja dan 185 orang tukang, dan jumlah tenaga kerja setelah perataan (leveling) yaitu sebanyak 790 orang yang terdiri dari 470 orang pekerja dan 320 orang tukang. Berdasarkan histogram sumber 
daya manusia, penggunaan tenaga kerja rencana dan realisasi terlalu banyak penurunan dan peningkatan penggunaan tenaga kerja diawal, ditengah dan diakhir jadwal pelaksanaan pekerjaan, sedangkan penggunaan tenaga kerja setelah perataan lebih efektif karena peningkatan dan penurunan kebutuhan tenaga kerja secara bertahap sehingga tidak terjadi fluktuasi penggunaan tenaga kerja yang tajam.

2. Tenaga kerja rencana memerlukan biaya sebesar Rp. 375.270.000,00 yang terdiri dari Rp. 207.270.000,00 untuk biaya pekerja dan Rp. 168.000.000,00 untuk biaya tukang. Tenaga kerja realisasi memerlukan biaya sebesar $\mathrm{Rp}$. 382.011.000,00 yang terdiri dari $\mathrm{Rp}$. 284.886.000,00 untuk biaya pekerja dan Rp. 97.125.000,00 untuk biaya tukang. Tenaga kerja setelah perataan (leveling) memerlukan biaya sebesar Rp. 375.270.000,00 yang terdiri dari Rp. 207.270.000,00 untuk biaya pekerja dan Rp. 168.000.000,00 untuk biaya tukang. Dengan demikian tenaga kerja rencana dan setelah perataan lebih hemat dengan biaya $\mathrm{Rp}$. 6.741.000,00 dibandingkan tenaga kerja realisasi.

\section{Saran}

Ada beberapa hal yang penulis sarankan sehubungan dengan pembahasan tugas akhir ini antara lain:

1. Dalam pelaksanaan suatu proyek sangat diperlukan perencanaan tenaga kerja untuk mencegah terjadinya fluktuasi penggunaan tenaga kerja yang akan berakibat terjadinya keterlambatan waktu penyelesaian proyek karena adanya keterbatasan tenaga kerja yang tersedia.

2. Dalam pelaksanaan proyek perlu memperhatikan faktor tenaga kerja, yaitu diusahakan agar setiap pekerjaan dapat diikuti dengan jumlah tenaga kerja yang merata pada tiap durasi pekerjaannya agar tidak terjadi fluktuasi yang tajam, yaitu dengan cara melakukan perataan sumber daya (Resource Leveling).

3. Dalam penelitian ini tidak membahas sumber daya material, untuk itu disarankan kepada peneliti selanjutnya melakukan penelitian tentang perataan sumber daya material untuk mengetahui penggunaan material yang efektif terhadap waktu penyelesaian proyek dengan metode perataan sumber daya (Resource Leveling) pada pelaksanaan proyek konstruksi.

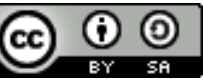

This is an open access article which means that all content is freely available without charge to the user or his/her institution. Jurnal Saintis allows the author(s) to hold the copyright without restriction. The copyright in the text of individual articles (including research articles, opinion articles, and abstracts) is the property of their respective authors distributed under the terms of the Creative Commons Attribution-ShareAlike 4.0 International License(https://creativecommons.org/licenses/by-sa/4.0/) which permits unrestricted use, distribution, and reproduction in any medium. Users are allowed to read, download, copy, distribute, search, or link to full-text articles in this journal without asking by giving appropriate credit, provide a link to the license, and indicate if changes were made. 